\title{
Brief notices
}

In this section, we acknowledge the receipt of recent works on Greek that have come to our editorial offices, and offer a brief characterization of their contents. All of the notices are authored by Brian Joseph except the one marked "(CGB)", which was written by Dr. Christopher G. Brown of The Ohio State University.

Crellin, Robert Samuel David. 2016. The Syntax and Semantics of the Perfect Active in Literary Koine Greek (Publications of the Philological Society, 47). Oxford: Wiley Blackwell, pp. vi +276 . [The key problem that author Crellin addresses in this work is to determine "the underlying semantics of the Ancient Greek perfect and pluperfect active" (p. 1). That it is a problem at all is demonstrated by the fact that "these forms, though bearing the label (plu)perfect active, cannot be relied on to correlate with a meaning which is regularly perfect, i.e. having reference to some completed past event, or active" (p. 1). He attacks this problem by drawing on contemporary theoretical frameworks for time reference and applying them to an extensive textual corpus (c. 850,000 words) of literary Koine sources, drawing especially on the works of Polybius, Josephus, Plutarch, and Appian. C's goal is to demonstrate that "none of the observed phenomena are per se intrinsic to the perfect, but are rather evidence ... of a lower level interaction in the domain of syntax and semantics between event and argument structure and ... a higher level semantic of the perfect itself, yielding the observed results in both tense-aspect and diathesis" (p. 20). This richly documented work, with a great deal of material from both primary Koine texts and secondary sources on the semantics of tense and aspect, is a welcome addition to the growing literature that addresses issues in the analysis of Greek with both theoretical sophistication and philological acumen.]

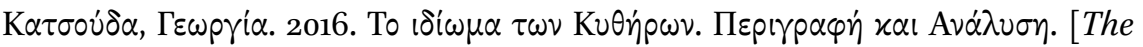
dialect of Kythera. Description and Analysis]. Preface by Angeliki Ralli. Athens: Etaireia Kytheriakon Meleton, pp. $316+$ DVD. [This work is a comprehensive study of the dialect of Kythera, providing systematic description of the most important phonetic, morphological, syntactical and lexical elements illustrated by numerous examples and a splendid DVD with recordings of dialect speakers. It compares the dialect of Kythera with that of neighboring islands and the Mani, and records numerous otherwise unattested words. Dr. Kat-

(C) BRIAN D. JOSEPH, 2017 | DOI: 10.1163/15699846-01701007

This is an open access article distributed under the terms of the Creative Commons 


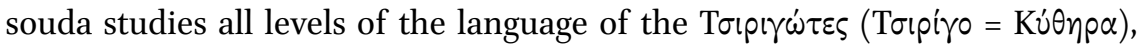
taking into account its variety. In addition to her own fieldwork, the author has synthesized a great volume of linguistic scholarship, documentation and non-literary sources in accordance with modern linguistic standards of classification, description and analysis. A brief history of Kythera provides a necessary introduction. Some 160 pages are devoted to morphology, the point of greatest divergence from Standard Modern Greek. The work is supplemented by a copious bibliography useful to all students of Greek dialects. This is an invaluable work that preserves and meticulously studies an important Greek dialect faced with extinction. (CGB)]

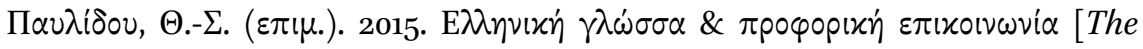

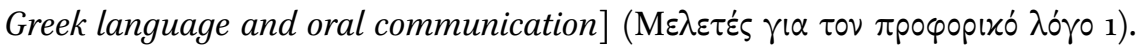
Thessaloniki: Instituto Neoellinikon Spudon (Idrima Manoli Triandafillidi), pp. 318. [This is the first volume in a new series of studies of oral language, and it contains 18 papers (some co-authored) by 21 different Greek scholars on a variety of issues having to do with various aspects of the study of oral communication and spoken language pertaining to the Greek language. Topics covered include negative-interrogatives as invitations, greetings, specific lexemes in discourse (e.g. en taksi 'all right', giati 'why?', re (as a term of address), and others), code-switching, reported speech, disagreement, repetition, gender identity, place as space imbued with social meaning, professional interaction, the language of focus groups, and Greek rock music. This rich collection breaks new ground in both the description and analysis of Greek.]

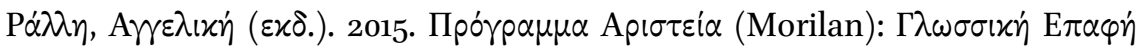

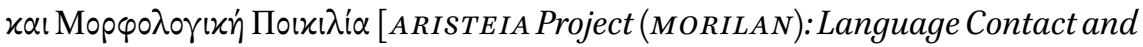
Morphological Variation] (Patras Working Papers in Linguistics, Volume 4). Patras: Ergastirio Neoellinikon Dialekton, Tmima Filologias, Panepistimio Patron, pp. 122 + xii. [This issue of the on-going series, Patras Working Papers in Linguistics, published since 2009 by the Laboratory of Modern Greek Dialects of the University of Patras, brings together several studies done under the auspices of an ARISTEIA project that ran from 2012 until 2015 and focused on the effects of language contact on Greek morphology. The particular contact languages of interest here were Italian and Turkish. The line-up of papers speaks for itself as to the wide range of topics covered by this research (titles given here in translation, as all of the papers are in Greek): "Morphology and language contact: Greek dialects in contact with Turkish and Italian-Final report on iomplementation of the project" (by Angeliki Ralli), "Plan and development of a morphological data base: The MORILAN database" (by Xaralambos 
Tsimbouris, Marios Andreou, and Nikos Koutsikos), "Morphological variation in Standard Modern Greek and in the dialects" (by Angeliki Ralli), "Environments of intense language contact and the borrowability of lexical items: Data from Griko and from Cappadocian" (by Mixalis Marinis and Angeliki Ralli), "Language change: Nominal borrowings in Heptanesian (Greek) and in Grecanico" (by Vasiliki Makri), and "The stages of morphological incorporation of lexical borrowings in Heptanesian (Greek)" (by Katerina Frangopoulou).]

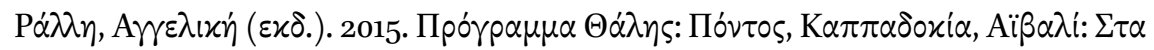

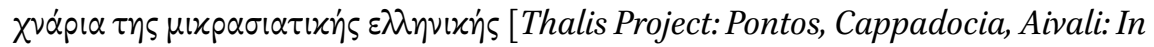
the footsteps of Asian Minor Greek]. Patras: Ergastirio Neoellinikon Dialekton, Tmima Filologias, Panepistimio Patron, pp. $178+$ xii. [This report of the Laboratory of Modern Greek Dialects of the University of Patras brings together nine research studies carried out under the auspices of the Thalis Project investigating various dialects that fall under the rubric of Asia Minor Greek. These studies are as follows (titles given here in translation, as all of the papers are in Greek): "General report of the work 'AMiGre' of the Thalis Project: 'Pontos, Cappadocia, Aivali: In the footsteps of Asia Minor Greek" (by Angeliki Ralli), "A digital corpus of texts for three Asia Minor dialects" (by Maria Koliopoulou, Io Manolessou, Theodoros Markopoulos, and Nikolaos Pantelidis), "Organization and codifying of oral sources in a multimodal cutting-edge database: The case of the AMiGre corpus" (by Dimitris Papazachariou and Athanasios Karasimos), "A multimodal system of archiving and managing written and oral sources for study of the language and of linguistic idioms" (by Nikitas Karanikolaos, Eleni Galiotou, Kostas Athanasakos, and Giorgos Koronakis), "LEPOKAM, a multimedia lexicon of the dialects of Pontos, Cappadocia, and Aivali: A theoretical approach and implementation" (by Giorgos Xidopoulos, Eleonora Dimela, Dimitra Melissaropoulou, Hristos Papanagiotou, and Angeliki Ralli), "The etymological model of a tridialectal on-line lexicon for the Asia Minor dialects of Cappadocia, Pontos, and Aivali-Mosxonisi (LEPOKAM): Questions and prospects" (by Simeon Tsolakidis), "Planning and development of a management system for a multimedia tridialectal lexicon" (by Eleni Galiotou, Nikitas Karanikolaos, Kostas Athanasakos, and Giorgos Koronakis), "Affixoids in the Pontic dialect: Presentation of a doctoral dissertation" (by Marianna Giouleka), and "Determining linguistic variants through student placements: The cases of Kydonia (Aivali)—Mosxonisia and Pontos" (by Arjiris Arhakis and Nikis Spiliopoulou).] 